\title{
Daunorubicin- $\mathrm{TiO}_{2}$ nanocomposites as a "smart" $\mathrm{pH}$-responsive drug delivery system
}

\author{
This article was published in the following Dove Press journal: \\ International Journal of Nanomedicine \\ II January 2012 \\ Number of times this article has been viewed
}

\author{
Haijun Zhang' \\ Cailian Wang' \\ Baoan Chen ${ }^{2,3}$ \\ Xuemei Wang ${ }^{3,4}$ \\ 'Department of Oncology, Zhongda \\ Hospital, Medical School, ${ }^{2}$ Department \\ of Hematology, Zhongda Hospital, \\ Medical School, ${ }^{3}$ Faculty of Oncology, \\ Medical School, ${ }^{4}$ State Key Laboratory \\ of Bioelectronics (Chien-Shiung Wu \\ Laboratory), Southeast University, \\ Nanjing, People's Republic of China
}

Correspondence: Baoan Chen Department of Hematology, Zhongda Hospital, Medical School, Southeast University, Nanjing 21 0009, People's Republic of China

Tel +862583272006

Fax +86258327 201।

Email cba8888@hotmail.com

\begin{abstract}
Daunorubicin (DNR) has a broad spectrum of anticancer activity, but is limited in clinical application due to its serious side effects. The aim of this study was to explore a novel "smart" pH-responsive drug delivery system (DDS) based on titanium dioxide $\left(\mathrm{TiO}_{2}\right)$ nanoparticles for its potential in enabling more intelligent controlled release and enhancing chemotherapeutic efficiency of DNR. DNR was loaded onto $\mathrm{TiO}_{2}$ nanoparticles by forming complexes with transition metal titanium to construct $\mathrm{DNR}-\mathrm{TiO}_{2}$ nanocomposites as a DDS. DNR was released from the DDS much more rapidly at $\mathrm{pH} 5.0$ and 6.0 than at $\mathrm{pH} 7.4$, which is a desirable characteristic for tumor-targeted drug delivery. DNR-TiO 2 nanocomposites induced remarkable improvement in anticancer activity, as demonstrated by flow cytometry, 3-(4,5-dimethylthiazol-2-yl)-2,5-diphenyltetrazolium bromide assay, and nuclear 4',6-diamidino2-phenylindole staining. Furthermore, the possible signaling pathway was explored by western blot. For instance, in human leukemia K562 cells, it was demonstrated that DNR-TiO 2 nanocomposites increase intracellular concentration of DNR and enhance its anticancer efficiency by inducing apoptosis in a caspase-dependent manner, indicating that $\mathrm{DNR}-\mathrm{TiO}_{2}$ nanocomposites could act as an efficient DDS importing DNR into target cancer cells. These findings suggest that "smart" DNR delivery strategy is a promising approach to cancer therapy.
\end{abstract}

Keywords: drug delivery system, daunorubicin, $\mathrm{pH}$-responsive, $\mathrm{TiO}_{2}$ nanoparticles, cancer, apoptosis

\section{Introduction}

With a broad spectrum of anticancer activity, daunorubicin (DNR) remains the firstline treatment for hematological malignancies and solid tumors. Unfortunately, its therapeutic effect is limited due to its serious side effects, including congestive heart failure, ${ }^{1}$ which presents a challenge for DNR in clinical application. Therefore, efforts should be made to develop new delivery techniques that reduce its side effects by altering its biodistribution, enhancing its deposition in tumor sites, and improving its therapeutic efficacy.

Recently, a so-called "smart" stimuli-sensitive drug delivery system (DDS) that responds to certain internal or external stimuli, such as $\mathrm{pH}$, temperature, and magnetism, represents a promising approach to improving the efficacy of cancer chemotherapy. ${ }^{2,3}$ It is well known that the extracellular $\mathrm{pH}$ of tumors is slightly more acidic than that of blood and normal tissue. Moreover, numerous $\mathrm{pH}$ gradients exist in the intracellular endocytic compartment $(\mathrm{pH}=4.5-6.5)$ where cells uptake a DDS via an endocytosis process. ${ }^{4}$ Therefore, an ideal anticancer DDS should retain the drug at $\mathrm{pH} 7.4$ but be able to quickly release it at a relatively lower $\mathrm{pH}$ (eg, $\mathrm{pH} 6.0$ or 5.0). An important 
breakthrough in this field is the preparation of a new class of nanosized DDS which can be internalized by tumor cells through the endocytosis pathway to avoid undesired drug release during drug transportation in blood circulation, thus improving effective release of the anticancer drug in tumor tissue or within tumor cells. ${ }^{5}$

Furthermore, there has been growing interest in metal nanomaterials as anticancer drug carriers recently, which represents a promising approach to tumors, although it is still under investigation. ${ }^{6,7}$ Barick et al reported a method for entrapping drugs at sites capable of complexing with transition metal ions and suggested that drug release is dependent on the $\mathrm{pH}$ of the medium and nature of the materials which encapsulate the drug. ${ }^{7}$ It is also suggested that this general strategy could be readily extended to other inorganic carriers. ${ }^{7}$

In view of these developments, the aim of this paper was to explore a novel "smart" $\mathrm{pH}$-responsive DDS based on titanium dioxide $\left(\mathrm{TiO}_{2}\right)$ nanoparticles that is chemically stable, environmentally friendly, and noncytotoxic. ${ }^{8,9}$ This DDS could provide a simple and easy way to enable intelligently controlled release of DNR and enhance its chemotherapeutic efficiency. To the best of the authors' knowledge, no study has been carried out on $\mathrm{TiO}_{2}$ nanoparticles for "smart" stimulisensitive DDS and is investigated here for the first time. In this study, DNR was loaded on $\mathrm{TiO}_{2}$ nanoparticles to construct DNR-TiO 2 nanocomposites as a DDS. Loading efficiency and influence of $\mathrm{pH}$ value on drug release behavior of the DDS were investigated by high-performance liquid chromatography. Additionally, tumor cellular uptake and cytotoxicity of the DDS were evaluated in K562 leukemia cells.

\section{Materials and methods}

\section{Chemicals and apparatus}

DNR was purchased from Pharmacia Italia SpA (Nerviano, Italy), and its stock solution was freshly prepared and stored in the dark at $4^{\circ} \mathrm{C}$. Phosphate buffer solution (PBS) with different $\mathrm{pH}$ value $(\mathrm{pH} 7.4,6.0,5.0)$ was prepared with double distilled water. $\mathrm{TiO}_{2}$ nanoparticles (P25; Evonik Industries AG, Essen, Germany) were suspended in sterilized PBS. Caspase 3 antibody, $\beta$-actin antibody, and horseradish peroxidase-conjugated immunoglobulin $\mathrm{G}$ antibody were obtained from Nanjing KeyGen Biotech Co, Ltd, (Nanjing, China). 3-(4,5-dimethylthiazol-2-yl)-2,5-diphenyltetrazolium bromide (MTT) and 4,6-Diamidino-2-phenylindole (DAPI) were obtained from Sigma-Aldrich Corporation (St Louis, MO) and stored in the dark. All other reagents were of analytical grades. The images of transmission electron microscope, electron diffraction, and high-resolution transmission electron microscope were obtained by a JEM-2100 transmission electron microscope (JEOL Ltd, Tokyo, Japan). Fluorescent microscopic images were shot on an Olympus IX51 inverted microscope (Olympus Corporation, Tokyo, Japan). Optical density at $492 \mathrm{~nm}$ was recorded by multiwell spectrophotometer reader (MK3; Thermo Labsystems, Vantaa, Finland).

\section{Construction of DNR-TiO, nanocomposites}

For a typical drug loading experiment, $2 \mathrm{~mL}$ aqueous solution of DNR (2 mg/mL) was added to $1 \mathrm{~mL}$ aqueous suspension of $\mathrm{TiO}_{2}$ nanoparticles $(10 \mathrm{mg} / \mathrm{mL})$. The above reaction mixture was continuously agitated with a stirrer at $50 \mathrm{~g}$ and kept overnight in the dark to construct nanocomposites of DNR-loaded $\mathrm{TiO}_{2}$ nanoparticles which acted as the DDS. DNR-loaded $\mathrm{TiO}_{2}$ nanoparticles were separated from the free-standing drug molecules through centrifugation at $5000 \mathrm{~g}$ for 20 minutes and the supernatant was determined by high-performance liquid chromatography, allowing estimation of drug encapsulation efficiency and loading efficiency. Encapsulation efficiency and loading efficiency were calculated by the following equations:

Encapsulation efficiency $(\%)=($ Amount of drug in DNR-TiO ${ }_{2}$ nanocomposites/initial amount of drug) $\times 100$

Loading efficiency $(\%)=\left(\right.$ Amount of drug in $\mathrm{DNR}-\mathrm{TiO}_{2}$ nanocomposites/amount of $\mathrm{DNR}-\mathrm{TiO}_{2}$ nanocomposites) $\times 100$

\section{Drug release}

Release behavior of DNR from DNR-TiO 2 nanocomposites was investigated at $\mathrm{pH} 5.0$ (approximate $\mathrm{pH}$ in endosomes or lysosomes), $\mathrm{pH} 6.0$ ( $\mathrm{pH}$ of the environment around the tumor), and $\mathrm{pH} 7.4$ (pH of physiological blood). DNR-loaded $\mathrm{TiO}_{2}$ nanoparticles $(20 \mathrm{mg}$ ) were dispersed in PBS (pH 7.4, $5 \mathrm{~mL}$ ) and transferred into a dialysis bag (Spectra/Por ${ }^{\circledR}$; Spectrum Laboratories, Inc, Rancho Dominguez, CA). The dialysis bag was then immersed in $95 \mathrm{~mL}$ PBS at $\mathrm{pH} 5.0,6.0$, or 7.4. The release medium was continuously agitated with a stirrer at $50 \mathrm{~g}$ and $37^{\circ} \mathrm{C}$. At predetermined time intervals, $2 \mathrm{~mL}$ of the external medium was collected and replaced with the same fresh PBS. The amount of released DNR in the medium was then determined by high-performance liquid chromatography (LC-310; Skyray Instrument, Nanjing, China).

\section{Cell culture}

K562 leukemia cells were obtained from Institute of Hematology, Chinese Academy of Medical Sciences (Beijing, China) 
and cultured in Gibco ${ }^{\circledR}$ Roswell Park Memorial Institute 1640 medium (Life Technologies, Grand Island, NY) supplemented with $10 \%$ heat-inactivated fetal bovine serum (Sigma-Aldrich), $100 \mathrm{U} / \mathrm{mL}$ penicillin (Sigma-Aldrich), and $100 \mu \mathrm{g} / \mathrm{mL}$ streptomycin (Sigma-Aldrich) at $37.0^{\circ} \mathrm{C}$ in humidified air with $5 \%$ carbon dioxide. Cells were in $\log$ phase prior to the following experiments to minimize experimental variations which occur with proliferative status.

\section{Cell internalization studies}

Cells $\left(1 \times 10^{5} / \mathrm{mL}\right)$ were seeded in six-well culture plates and grown overnight. They were then treated with either DNR or DNR-TiO ${ }_{2}$ nanocomposites (DNR concentration $0.5 \mu \mathrm{g} / \mathrm{mL}$ ) for 6 hours. To visualize the cellular uptake of DNR with different treatments, the cells were examined by fluorescent microscopy $\left(\lambda_{\text {ex }} 488 \mathrm{~nm}, \lambda_{\text {em }} 515 \mathrm{~nm}\right)$ after incubation for 6 hours. Furthermore, the cells were resuspended in PBS after being washed three times. DNR uptake was analyzed by FACSCalibur ${ }^{\mathrm{TM}}$ flow cytometer (BD Biosciences, San Jose, CA); the gate was arbitrarily set for the detection of green fluorescent DNR.

\section{Assay of anticancer activity}

Cytotoxicity of $\mathrm{TiO}_{2}$ nanoparticles, DNR, and DNR-TiO nanocomposites was studied in leukemia K562 cells with MTT assays. Cells $\left(1 \times 10^{5} / \mathrm{mL}\right)$ were seeded in 96-well plates and incubated for 24 hours. Growth medium was then replaced with $200 \mu \mathrm{L}$ of the preprepared medium containing either free DNR or DNR-TiO 2 nanocomposites (DNR concentration $0,0.125,0.25,0.5$, and $1 \mu \mathrm{g} / \mathrm{mL}$ ). Cells were treated by $\mathrm{TiO}_{2}$ nanoparticles alone as well to evaluate its cytotoxicity. Cells without any treatment were used as the control group. Cells were further incubated for 48 hours, and relative anticancer activity was assessed with MTT assays. After 48 hours, MTT assay was carried out. In brief, MTT solutions were added after treatment and incubated for an additional 4 hours. Dimethyl sulfoxide (Sinopharm Chemical Reagent Co Ltd, Shanghai, China) was added to solubilize the formazan crystal, and optical density $492 \mathrm{~nm}$ was recorded. Cell viability (\%) was calculated as follows:

Optical density $_{492 \mathrm{~nm} \text { in test cells }} /$ Optical density ${ }_{492 \mathrm{~nm} \text { in control cells }} \times 100$

\section{DAPI staining}

Cells were treated with the above methods for 48 hours, and were then fixed with $4 \%$ polyoxymethylene prior to washing with PBS. The washed cells were then stained with $1 \mathrm{mg} / \mathrm{mL}$ DAPI for 15 minutes in the dark. Staining images were recorded with fluorescent microscope.

\section{Western blot analysis}

After the different treatments, caspase 3 expression was detected by western blot. In brief, total protein was isolated, subjected to sodium dodecyl sulfate polyacrylamide gel electrophoresis, and transferred to a polyvinylidene fluoride membrane. After being blocked, the membrane was incubated with primary polyclonal antibodies either anti-caspase 3 or anti- $\beta$-actin overnight at $4{ }^{\circ} \mathrm{C}$, and subsequently incubated with horseradish peroxidase-conjugated immunoglobulin $\mathrm{G}$ antibody as the secondary antibody for 1 hour at room temperature. The protein bands were detected by an enhanced electrochemiluminescence detection system (ECL system, Amersham, UK). After normalization by corresponding $\beta$-actin expression, protein expression levels of caspase 3 were determined by densitometry scans.

\section{Statistical analysis}

All data are presented as mean \pm standard deviation. F-test was used for significance testing, and $P<0.05$ was considered to be statistically significant. All tests were performed using IBM SPSS software (v 13.0; SPSS Inc, Chicago, IL).

\section{Results and discussion \\ Characterization of $\mathrm{TiO}_{2}$ nanoparticles}

Transmission electron microscopic images of $\mathrm{TiO}_{2}$ nanoparticles are shown in Figure 1. Observed $\mathrm{TiO}_{2}$ nanoparticles had a spherical shape with a diameter of about $25 \mathrm{~nm}$ (Figure 1A). The particles had dimensions suitable for escaping rapid renal excretion, as well as avoiding components of the reticular endothelial system. Thus, potentially passive targeting of drugs to tumors was facilitated via enhanced permeation and retention effect, and drug accumulation in tumor cells after endocytosis was increased. ${ }^{4}$ Also, the selectedarea electron diffraction (Figure 1B) patterns confirmed that $\mathrm{TiO}_{2}$ nanoparticles were single crystalline with a

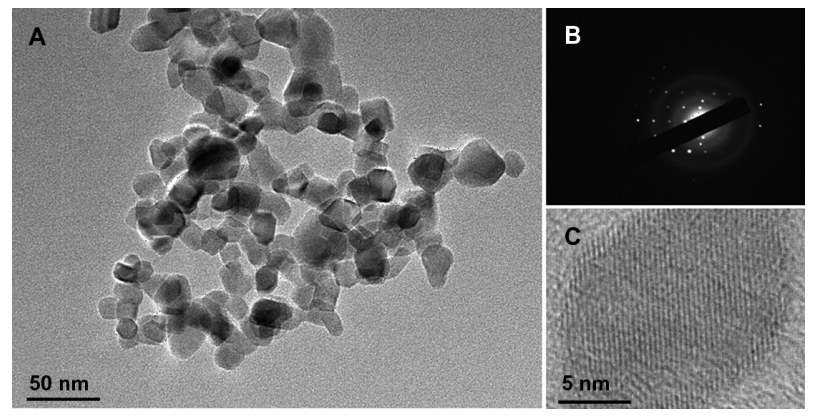

Figure I Transmission electron microscopic image (A), electron diffraction patterns (B), and high-resolution transmission electron microscopic image (C) of titanium dioxide nanoparticles. 
hexagonal-wurtzite structure. The fine microstructures of $\mathrm{TiO}_{2}$ nanoparticles were further characterized by high-resolution transmission electron microscope (Figure 1C), which showed that $\mathrm{TiO}_{2}$ nanoparticles were highly crystalline.

\section{DNR-TiO 2 nanocomposites as a DDS}

A previous study showed that the analog of DNR, doxorubicin, has three potential metal binding sites. ${ }^{7}$ One is the nitrogen atom in the sugar moiety and the other two are the chelating sites of quinone and phenolic oxygens on both sides of the anthracycline aromatic moiety. ${ }^{7}$ In the present study, the capacity of $\mathrm{TiO}_{2}$ nanoparticles as a drug carrier for loading DNR was explored. Color change of pure DNR from red to orange was observed during the loading process, indicating that DNR molecules could form complexes with $\mathrm{TiO}_{2}$ nanoparticles. The more likely metal binding sites of DNR were deduced to be the two keto-phenolate functions: $\mathrm{C}=\mathrm{O}$ and $\mathrm{C}-\mathrm{O}^{-}$(six-membered chelate), due to the low affinity of metal ions for the nitrogen atom donor. In addition, DNR, which is positively charged, can be easily self-assembled onto the surface of $\mathrm{TiO}_{2}$ nanoparticles through electrostatic interaction as the relative surface of $\mathrm{TiO}_{2}$ nanoparticles is negatively charged in $\mathrm{pH} 7.4$ aqueous solutions. ${ }^{8,10}$ Thus, the authors believe that DNR was absorbed onto the $\mathrm{TiO}_{2}$ nanoparticles by forming complexes with transition metal titanium and by electrostatic interaction. Figure 2 shows a proposed schematic representation of DNR loading onto $\mathrm{TiO}_{2}$ nanoparticles through the formation of $\mathrm{DNR}-\mathrm{TiO}_{2}$ nanocomposites as a DDS. Encapsulation efficiency and loading efficiency of DNR-loaded $\mathrm{TiO}_{2}$ nanoparticles were assessed and calculated as $65.46 \% \pm 6.82 \%$ and $20.63 \% \pm 3.55 \%$, respectively. Results show that DNR-loaded $\mathrm{TiO}_{2}$ nanoparticles may efficiently act as anticancer drug delivery carrier.

\section{$\mathrm{pH}$-triggered drug release behavior}

As shown in Figure 3, release of drug molecules depended on $\mathrm{pH}$ of the medium and release time. Drug release at pH 7.4 was slow and sustained, with release ratio at about $18 \%$ within 48 hours. However, at lower $\mathrm{pH}$, DNR release rate was much faster, with approximately $67 \%$ (pH 6.0) and $86 \%$ ( $\mathrm{pH} 5.0$ ) of the drug released within 48 hours. Protonation of the drug (dissociation of $\mathrm{DNR}^{-\mathrm{TiO}_{2}}$ nanocomposites) occurred at lower $\mathrm{pH}$, which released chemisorbed drug molecules into the medium. Furthermore, surface charges of $\mathrm{TiO}_{2}$ nanoparticles turned positive at lower $\mathrm{pH}$, which blunted the electrostatic interaction of $\mathrm{DNR}$ and $\mathrm{TiO}_{2}$ nanoparticles

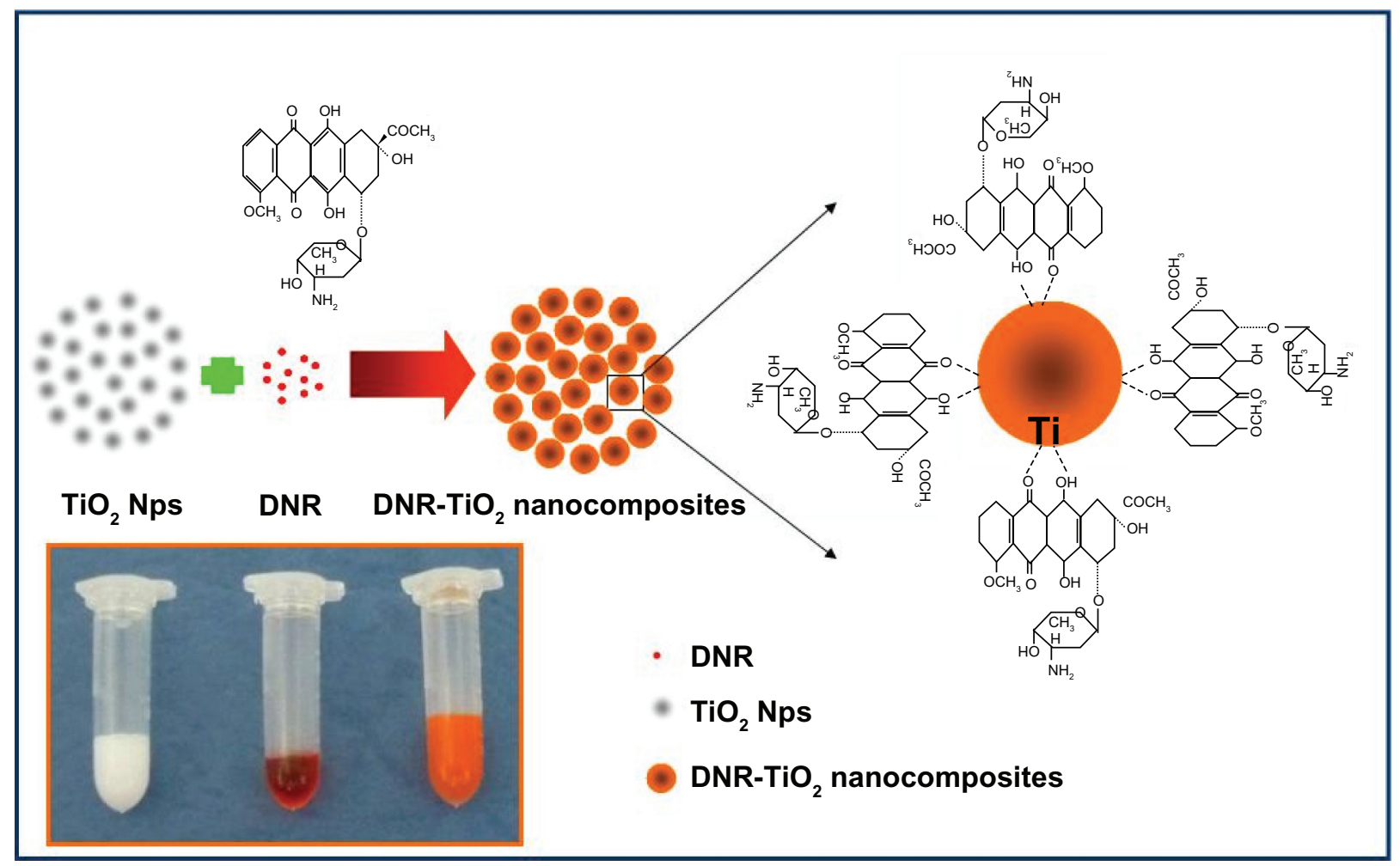

Figure 2 Schematic representation and photographic image (inset) of daunorubicin loading onto titanium dioxide nanoparticles through the formation of daunorubicintitanium dioxide nanocomposites.

Abbreviations: DNR, daunorubicin; Nps, nanoparticles; $\mathrm{TiO}_{2}$, titanium dioxide. 


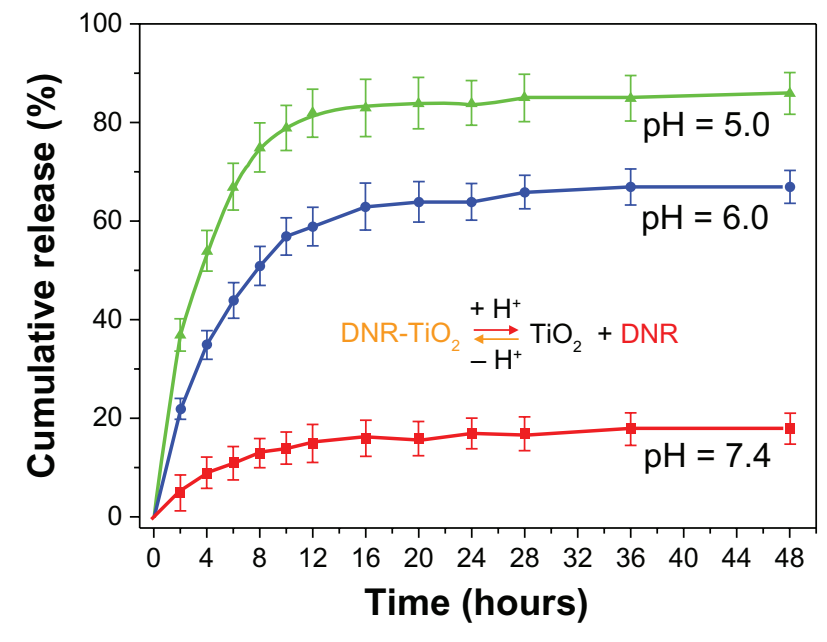

Figure 3 In vitro daunorubicin release behavior at $\mathrm{pH} 7.4,6.0$, and 5.0. Abbreviations: DNR, daunorubicin; $\mathrm{DNR}_{-} \mathrm{TiO}_{2}$, daunorubicin-titanium dioxide nanocomposites; $\mathrm{TiO}_{2}$, titanium dioxide.

and facilitated the drug release process. These results demonstrate $\mathrm{pH}$-triggered drug release behavior from the novel DDS, which is of particular interest. It may be hypothesized that most DNR will remain in the carrier for a considerable time period at normal physiological conditions ( $\mathrm{pH} 7.4$ ), indicating the potential for prolonged DNR retention time in blood circulation and thereby greatly reducing the side effects to normal tissues. On the other hand, once DNRloaded $\mathrm{TiO}_{2}$ nanoparticles are taken up by tumor cells via endocytotic process, a faster release may occur at lower local $\mathrm{pH}$, ie, surrounding the tumor site or inside the endosome and lysosome of tumor cells, leading to significant improvement in cancer treatment efficacy.

\section{Cellular uptake}

Fluorescent DNR allows facile observation of the cellular uptake of free DNR and DNR-loaded $\mathrm{TiO}_{2}$ nanoparticles by K562 cells, quantitatively detected by flow cytometry without additional markers. Figure 4A illustrates the typical results of fluorescent microscopy of intracellular DNR. The internalization of DNR loaded onto $\mathrm{TiO}_{2}$ nanoparticles (Figure 4A, right panel) was much higher after 6 hours of incubation compared with the free DNR (Figure 4A, left panel), resulting in stronger fluorescence intensity in K562 cells. The relative intracellular fluorescence intensity of DNR analyzed by flow cytometry allows quantitative comparison of the cases mentioned above (Figure 4B). Intracellular fluorescence intensity for the group of DNR$\mathrm{TiO}_{2}$ nanocomposites produced $65 \% \pm 3.7 \%$ enhancements compared to the group of free DNR. These results clearly show that DNR-TiO ${ }_{2}$ nanocomposites as a DDS increased

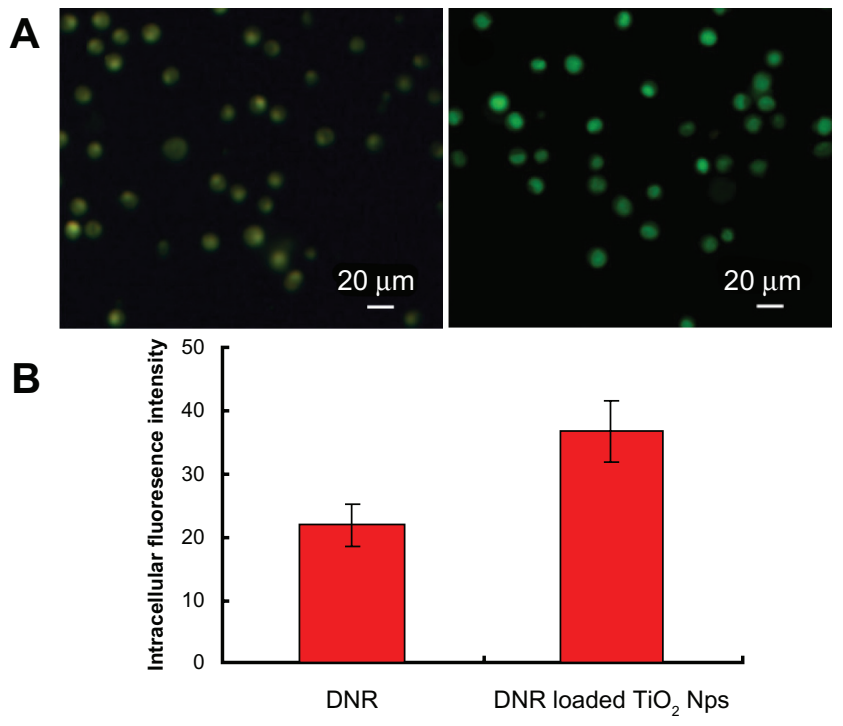

Figure 4 Fluorescent microscopic images of K562 cells (A) treated with free daunorubicin (left panel) and titanium dioxide nanoparticles loading daunorubicin as a drug delivery system (right panel). Comparison of the respective average intracellular fluorescence intensity is also shown (B). Concentrations of daunorubicin and titanium dioxide nanoparticles are $0.5 \mu \mathrm{g} / \mathrm{mL}$ and $10 \mu \mathrm{g} / \mathrm{mL}$, respectively. Note: Data expressed as mean \pm standard deviation $(n=3)$.

Abbreviations: DNR, daunorubicin; $\mathrm{Nps}$, nanoparticles; $\mathrm{TiO}_{2}$, titanium dioxide.

the cellular uptake of DNR substantially. $\mathrm{TiO}_{2}$ nanoparticles demonstrated significant properties of a drug carrier, which represents a promising approach to cancer therapy.

\section{Anticancer activity in vitro}

A common characteristic of a nanoparticle-based DDS is the rapid internalization and intracellular localization into acidic endosomes and/or lysosomes of cells. ${ }^{11,12}$ Due to this common pathway of cellular uptake, there has been significant interest in methods to engineer acid-triggered responses from DDS for rapid intracellular release of therapeutics. ${ }^{13}$ To further explore the anticancer efficiency of the novel $\mathrm{pH}$-responsive DDS based on $\mathrm{TiO}_{2}$ nanoparticles for DNR, K562 cells were cultured with free DNR at different concentrations $(0,0.125$, $0.25,0.5$, and $1 \mu \mathrm{g} / \mathrm{mL}$ ) and $\mathrm{DNR}-\mathrm{TiO}_{2}$ nanocomposites with equivalent DNR concentration for 48 hours. Cytotoxicity results were estimated by MTT assay (Figure 5).

A cytotoxicity test of the nanomaterial is the first-level evaluation before its biomedical applications. When treated by $\mathrm{TiO}_{2}$ nanoparticles, about $95 \%$ of the cells survived (Figure 5, blue line), which is consistent with a previous report. ${ }^{10}$ The lack of cytotoxicity of $\mathrm{TiO}_{2}$ nanoparticles thus ensures a wide potential range of applications in the field of biomedical science and cancer therapy. Compared with DNR alone (Figure 5, green line), viability of K562 cells treated by DNR$\mathrm{TiO}_{2}$ nanocomposites obviously decreases (Figure 5, black line). Results also indicate that with increasing concentrations 


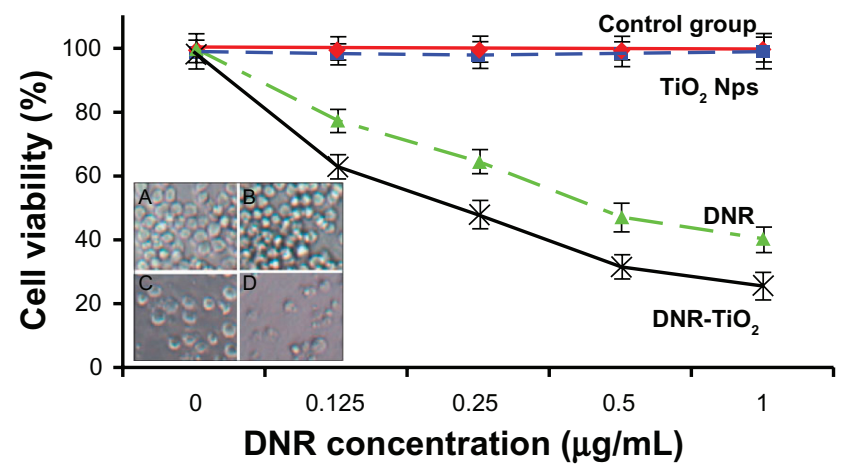

Figure 5 Cytotoxic effect of daunorubicin or daunorubicin-titanium dioxide nanocomposites on K562 leukemia cells. Microscopic images of K562 cells after different treatments for $\mathbf{4 8}$ hours are shown inset: (A) untreated cells as control, (B) titanium dioxide nanoparticles, (C) daunorubicin alone, and (D) daunorubicintitanium dioxide nanocomposites. Concentrations of daunorubicin and titanium dioxide nanoparticles are $1 \mu \mathrm{mol} / \mathrm{L}$ and $10 \mu \mathrm{g} / \mathrm{mL}$, respectively.

Note: Data expressed as mean \pm standard deviation $(n=3)$.

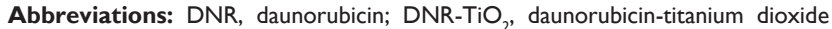
nanocomposites; $\mathrm{Nps}$, nanoparticles; $\mathrm{TiO}_{2}$, titanium dioxide.

of DNR, lethality increased, suggesting a dose-dependent effect in vitro. Increased cytotoxicity may be due to improved DNR cellular uptake by $\mathrm{DNR}_{-} \mathrm{TiO}_{2}$ nanocomposites (as illustrated above) and to the induced release of DNR from $\mathrm{TiO}_{2}$.

The process of controlled release is of particular interest in achieving DNR delivery with $\mathrm{TiO}_{2}$. At normal physiological conditions ( $\mathrm{pH} 7.4$ ), it is expected that most DNR conjugated with $\mathrm{TiO}_{2}$ will remain in the carrier for a considerable time period. As well documented, a nanoparticlebased DDS could be internalized through the endocytosis pathway. ${ }^{14}$ In the endocytic compartment, $\mathrm{pH}$ values range $4.5-6.5 ;{ }^{15}$ and at this low $\mathrm{pH}$, protonation of the drug occurs.
Protonation will then trigger the release of chemisorbed drug molecules and turn surface charges of $\mathrm{TiO}_{2}$ nanoparticles to positive, blunting the electrostatic interaction of DNR and $\mathrm{TiO}_{2}$ nanoparticles which facilitates the drug release process. Consequently, a faster release of DNR from DNR-TiO, nanocomposites occurs once the carrier is taken up by the tumor cells via endocytic process. Therefore, a sufficiently high concentration of DNR can be generated within a reasonably short period of time, thereby greatly promoting the cell-killing effects efficiently. Considering that a high dose of DNR may lead to serious side effects, especially congestive heart failure, ${ }^{1}$ DNR-TiO 2 nanocomposites as a DDS improves therapeutic efficacy without a high usage of DNR, thus potentially minimizing its toxic side effects.

As shown in the inset of Figure 5, optical microscopic observations confirm MTT assay results. K562 cells without any treatment attached to the plate with normal spherical shape (Figure 5A). Notably, cells treated with $\mathrm{TiO}_{2}$ nanoparticles had no morphological changes (Figure 5B). It is obvious that DNR (Figure 5C) and the even more effective DNR-TiO ${ }_{2}$ nanocomposites (Figure 5D) could kill more cancer cells and cause more significant morphological changes, indicating an increased probability in cell death.

\section{Morphologic characterization of apoptosis}

To explore the mechanism of distinct improvement in anticancer activity induced by the novel $\mathrm{pH}$-responsive DDS, nuclear DAPI staining was performed. To confirm the existence of
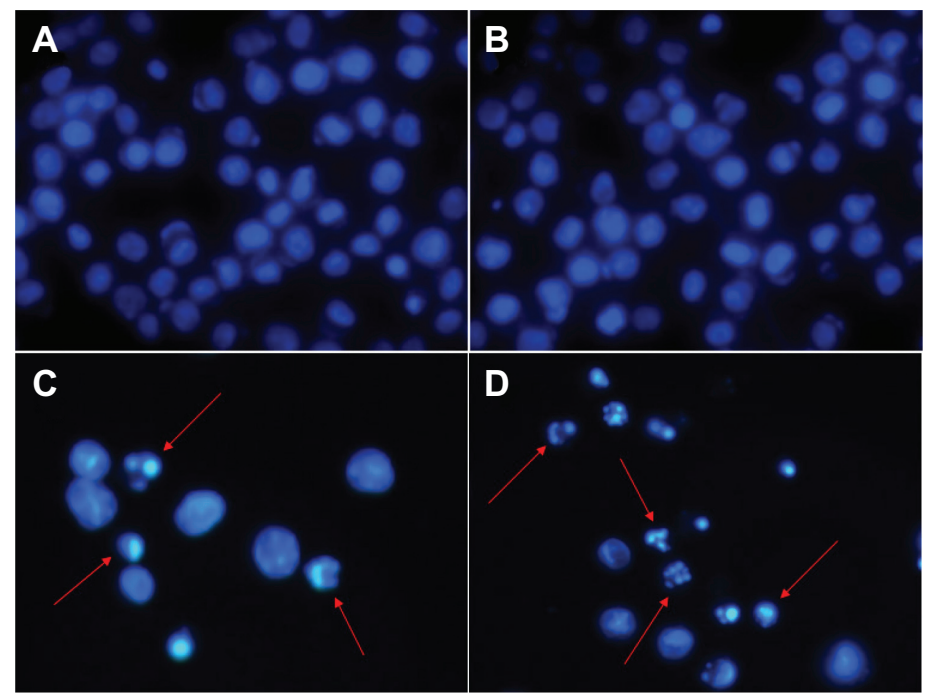

Figure 6 Nuclear morphologic changes of K562 leukemia cells after different treatments for 48 hours: (A) untreated cells as control, (B) titanium dioxide nanoparticles, (C) daunorubicin alone, and (D) daunorubicin-titanium dioxide nanocomposites. Concentrations of daunorubicin and titanium dioxide nanoparticles are $0.5 \mu \mathrm{g} / \mathrm{mL}$ and $10 \mu \mathrm{g} / \mathrm{mL}$, respectively.

Notes: Magnification: $\times 400$. Arrows indicate cells with apoptotic nuclear condensation and fragmentation. 


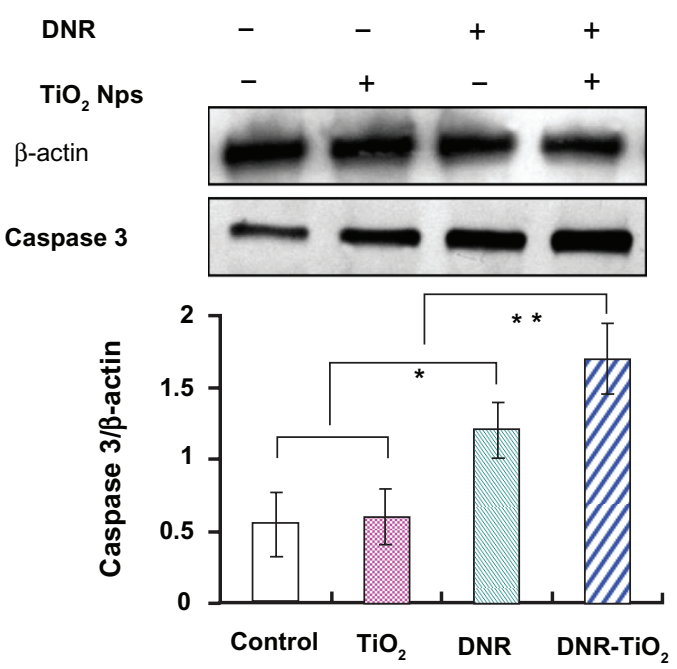

Figure 7 Expression of caspase 3 in $\mathrm{K} 562$ cells by western blotting analysis. After normalization by corresponding $\beta$-actin expression, protein expression levels of caspase 3 were determined by densitometry scans to obtain quantitative data. Note: Data expressed as mean \pm standard deviation $(n=3)$.

Abbreviations: DNR, daunorubicin; $\mathrm{DNR}^{-\mathrm{TiO}_{2}}$, daunorubicin-titanium dioxide nanocomposites; $\mathrm{Nps}$, nanoparticles; $\mathrm{TiO}_{2}$, titanium dioxide.

apoptosis, morphological changes of the cells were studied. Evaluation of normal or apoptotic cells depends on morphological characterization. Normal nuclei (smooth nuclear) and apoptotic nuclei (condensed or fragmented chromatin) were easily distinguished. As shown in Figure 6, nuclear morphology analysis showed characteristic apoptotic changes, such as chromatin condensation, convoluted nuclei with cavitations, fragmentation of the nucleus, and apoptotic bodies in K562 cells after treatment with DNR and DNR-TiO 2 nanocomposites. There was almost no apoptotic evidence in the control group (Figure 6A) and $\mathrm{TiO}_{2}$ group (Figure 6B). When cells were treated with DNR-TiO 2 nanocomposites (Figure 6D), typical apoptotic morphology was more apparent than that of cells treated with DNR alone (Figure 6C). These findings strongly indicate that DNR-TiO, nanocomposites killed the cancer cells by inducing apoptosis rather than necrosis.

\section{Caspase 3 activity during induced apoptosis}

Nuclear DNA is the main subcellular site of DNR action for its anticancer activity. DNR can efficiently accumulate in nucleus, intercalate DNA, and act as a cytostatic and apoptotic agent against tumor cells. To explore the possible signaling pathways through which $\mathrm{DNR}-\mathrm{TiO}_{2}$ nanocomposites induced distinct improvement in anticancer activity, the changes in expression levels of the apoptosis-regulating protein, caspase 3 , were examined by western blot. As shown in Figure 7, when K562 cells were treated with DNR and DNR-TiO 2 nanocomposites for 48 hours, levels of caspase 3 protein were significantly upregulated compared to control group. Meanwhile, the upregulated levels of caspase 3 protein in $\mathrm{DNR}_{-} \mathrm{TiO}_{2}$ nanocomposites group were slightly higher than those in DNR group $(P<0.05)$. However, the caspase 3 protein was not obviously altered when the cells were treated with $\mathrm{TiO}_{2}$ nanoparticles $(P>0.05)$. Caspase activation is generally considered

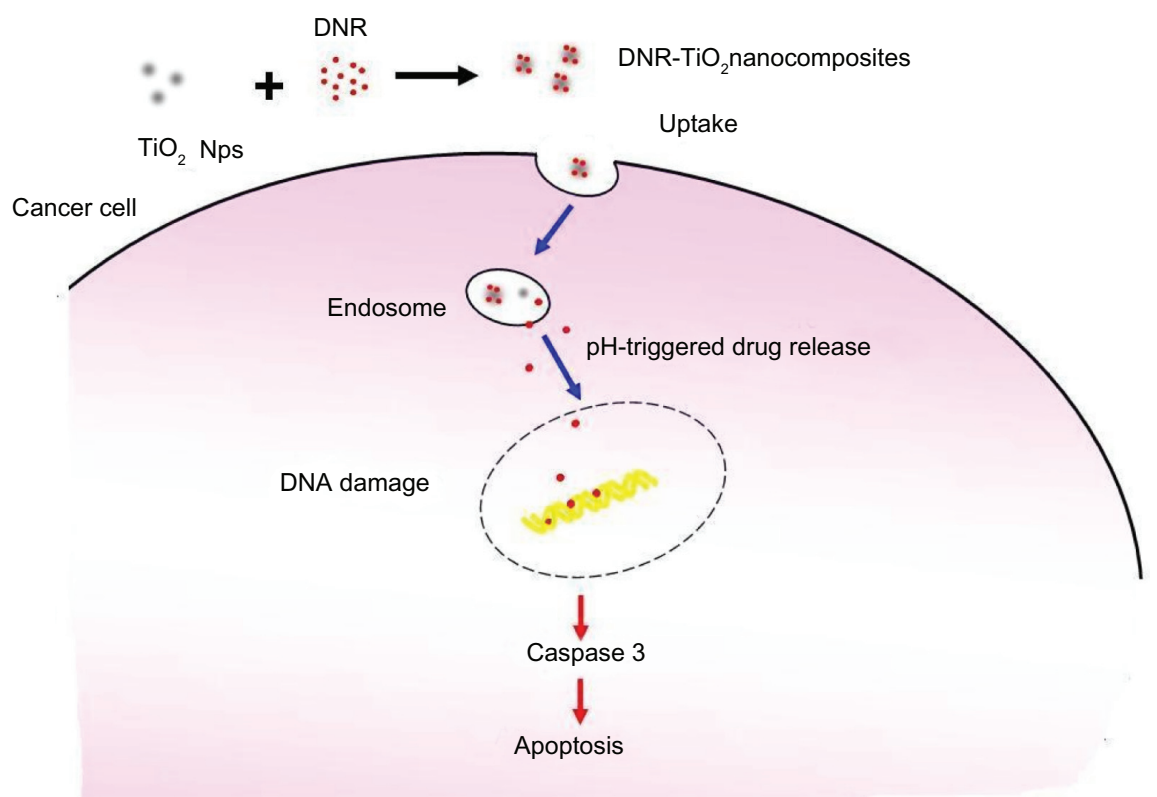

Figure 8 Schematic illustration of the possible process of distinct improvement in anticancer activity by the novel pH-responsive drug delivery system based on titanium dioxide nanoparticles for daunorubicin.

Abbreviations: DNR, daunorubicin; $\mathrm{Nps}$, nanoparticles; $\mathrm{DNR}-\mathrm{TiO}_{2}$, daunorubicin-titanium dioxide nanocomposites; $\mathrm{TiO}_{2}$, titanium dioxide. 
to be a key hallmark of apoptosis, and caspase 3 is the main effector caspase that is involved in apoptosis. ${ }^{16}$ These results indicate that the studied DDS induces distinct improvement in anticancer activity in a caspase-dependent manner.

Based on the above studies, Figure 8 schematically illustrates the possible processes that lead to the distinct improvement in anticancer activity. DNR can be easily self-assembled onto the surface of $\mathrm{TiO}_{2}$ nanoparticles by forming complexes with transition metal titanium to construct DNR-TiO nanocomposites as a DDS. Drug release shows strong dependence on $\mathrm{pH}$ value, which is higher at lower $\mathrm{pH}$. Thereby, $\mathrm{TiO}_{2}$ nanoparticles load an amount of DNR molecules and carry them into cells, increasing intracellular concentration of DNR dramatically, and thus enhancing the suppression of cancer cell proliferation. The therapeutic concentration inside cancer cells is increased, which enhances the efficiency of drugs per dosage and, accordingly, solves some of the limitations of anticancer drugs, thereby exhibiting tremendous application potential in cancer therapy. Finally, apoptosis, a preferred mode of killing cancer cells in cancer therapy, is induced synergistically, resulting in a distinct improvement in anticancer activity.

\section{Conclusion}

In the present study, a $\mathrm{pH}$-responsive nanocomposite composed of self-assembled DNR and $\mathrm{TiO}_{2}$ nanoparticles was developed for a "smart" stimuli-sensitive DDS. Drug release from the DDS was significantly accelerated by decreasing $\mathrm{pH}$ from 7.4 to 5.0, which is of particular interest to cancer therapy due to the acidic extracellular tumor environment and intracellular endosomal and/or lysosomal compartments. DNR-TiO nanocomposites increased the accumulation of DNR in tumor cells and induced caspase-dependent apoptosis, enhancing anticancer activity and potentially minimizing the toxic side effects of DNR. All these characteristics demonstrate that the novel $\mathrm{pH}$-responsive DDS based on $\mathrm{TiO}_{2}$ nanoparticles for DNR is a promising strategy for clinical practice.

\section{Acknowledgment}

This work was supported by the National Key Basic Research Program (2010CB732404) and the National Nature Science Foundation of China (30740062, 30872970).

International Journal of Nanomedicine

\section{Publish your work in this journal}

The International Journal of Nanomedicine is an international, peerreviewed journal focusing on the application of nanotechnology in diagnostics, therapeutics, and drug delivery systems throughout the biomedical field. This journal is indexed on PubMed Central, MedLine, CAS, SciSearch ${ }^{\circledR}$, Current Contents ${ }^{\circledR} /$ Clinical Medicine,

\section{Disclosure}

The authors report no conflicts of interest in this work.

\section{References}

1. Petre CE, Dittmer DP. Liposomal daunorubicin as treatment for Kaposi’s sarcoma. Int J Nanomedicine. 2007;2(3):277-288.

2. Hidaka M, Yoshida R. Self-oscillating gel composed of thermosensitive polymer exhibiting higher LCST. $J$ Control Release. 2011;150(2):171-176.

3. Wu WW, Chen BA, Cheng, JA, et al. Biocompatibility of Fe3O4/DNR magnetic nanoparticles in the treatment of hematologic malignancies. Int J Nanomedicine. 2010;5:1079-1084.

4. Zhang DW, Zhang H, Nie J, Yang J. Synthesis and self-assembly behavior of $\mathrm{pH}$-responsive amphiphilic copolymers containing ketal functional groups. Polym Int. 2010;59(7):967-974.

5. Xiong XB, Ma ZS, Lai R, Lavasanifar A. The therapeutic response to multifunctional polymeric nano-conjugates in the targeted cellular and subcellular delivery of doxorubicin. Biomaterials. 2010; 31(4):757-768.

6. Zhang HJ, Chen BA, Jiang H, Wang CL, Wang HP, Wang XM. A strategy for $\mathrm{ZnO}$ nanorod mediated multi-mode cancer treatment. Biomaterials. 2011;32(7):1906-1914.

7. Barick KC, Nigam S, Bahadur D. Nanoscale assembly of mesoporous ZnO: a potential drug carrier. J Mater Chem. 2010;20(31):6446-6452.

8. Song M, Zhang RY, Dai YY, et al. The in vitro inhibition of multidrug resistance by combined nanoparticulate titanium dioxide and UV irradiation. Biomaterials. 2006;27(23):4230-4238.

9. Li QN, Wang XM, Lu XH, et al. The incorporation of daunorubicin in cancer cells through the use of titanium dioxide whiskers. Biomaterials. 2009;30(27):4708-4715.

10. Zhang HJ, Jiang H, Wang HP, Zhao J, Chen BA, Wang XM. Ultrasound mediated drug-loaded nanoparticles crossing cell membranes as a new strategy to reverse cancer multidrug resistance. J Nanosci Nanotechnol. 2011;11(3):1834-1840.

11. Bareford LA, Swaan PW. Endocytic mechanisms for targeted drug delivery. Adv Drug Delivery Rev. 2007;59(8):748-758.

12. Gillies ER, Goodwin AP, Fréchet JM. Acetals as pH-sensitive linkages for drug delivery. Bioconjug Chem. 2004;15(6):1254-1263.

13. Luong A, Issarapanichkit T, Kong SD, Fong R, Yang J. pH-sensitive, N-ethoxybenzylimidazole (NEBI) bifunctional crosslinkers enable triggered release of therapeutics from drug delivery carriers. Org Biomol Chem. 2010;8(22):5105-5109.

14. Yoo HS, Lee KH, Oh JE, Park TG. In vitro and in vivo anti-tumor activities of nanoparticles based on doxorubicin-PLGA conjugates. J Control Release. 2000;68(3):419-431.

15. Prabaharan M, Grailer JJ, Pilla S, Steeber DA, Gong SQ. Amphiphilic multi-arm-block copolymer conjugated with doxorubicin via $\mathrm{pH}-$ sensitive hydrazone bond for tumor-targeted drug delivery. Biomaterials. 2009;30(29):5757-5766.

16. Ghavami S, Hashemi M, Ande SR, et al. Apoptosis and cancer: mutations within caspase genes. J Med Genet. 2009;46(8):497-510.

Journal Citation Reports/Science Edition, EMBase, Scopus and the Elsevier Bibliographic databases. The manuscript management system is completely online and includes a very quick and fair peer-review system, which is all easy to use. Visit http://www.dovepress.com/ testimonials.php to read real quotes from published authors. 